\title{
Rab15 alternative splicing is altered in spheres of neuroblastoma cells
}

\author{
THI VAN HUYEN PHAM ${ }^{1}$, TRI BUDI HARTOMO ${ }^{2}$, MYEONG JIN LEE ${ }^{2}$, DAIICHIRO HASEGAWA ${ }^{3}$, \\ TOSHIAKI ISHIDA ${ }^{3}$, KEIICHIRO KAWASAKI ${ }^{3}$, YOSHIYUKI KOSAKA ${ }^{3}$, TOMOTO YAMAMOTO ${ }^{1,2}$, \\ SATORU MORIKAWA ${ }^{1,2}$, NOBUYUKI YAMAMOTO ${ }^{1}$, IKUKO KUBOKAWA ${ }^{1}$, TAKESHI MORI ${ }^{1}$, \\ TOMOKO YANAI $^{1}$, AKIRA HAYAKAWA ${ }^{1}$, YASUHIRO TAKESHIMA ${ }^{1}$, KAZUMOTO IIJIMA ${ }^{1}$, \\ MASAFUMI MATSUO ${ }^{4}$, HISAHIDE NISHIO ${ }^{1,2}$ and NORIYUKI NISHIMURA ${ }^{1,2}$ \\ Departments of ${ }^{1}$ Pediatrics and ${ }^{2}$ Epidemiology, Kobe University Graduate School of Medicine; \\ ${ }^{3}$ Department of Hematology and Oncology, Hyogo Children's Hospital; ${ }^{4}$ Department \\ of Medical Rehabilitation, Kobe Gakuin University, Kobe, Japan
}

Received November 15, 2011; Accepted December 29, 2011

DOI: 10.3892/or.2012.1731

\begin{abstract}
Neuroblastoma is an aggressive pediatric tumor that accounts for $15 \%$ of cancer-related deaths in children. More than half of high-risk neuroblastoma patients develop tumor relapse that is lethal in most cases. A small population of tumor-initiating cells (TICs), recently identified from high-risk neuroblastoma patients as spheres, is believed to be responsible for tumor relapse. Rab family small $\mathrm{G}$ proteins are essential in controlling membrane traffic and their misregulation results in several cancers. Rab15 was originally isolated as a brain-specific Rab protein regulating the endocytic recycling pathway and was recently identified as a downstream target of the neural transcription factor Atoh1. Previously, we identified two alternatively spliced Rab15 isoforms in neuroblastoma cells and showed a significant correlation between Rab15 expression and neuronal differentiation. As aberrant alternative splicing is intimately associated with an increasing number of cancers, its use as a new diagnostic and/or prognostic biomarker has attracted considerable attention. In the present study, we explored cancer-associated changes of Rab15 alternative splicing in neuroblastoma TICs. We found that Rab15 alternative splicing generated two novel isoforms designated as Rab15 ${ }^{\mathrm{AN} 2}$ and Rab15 $5^{\mathrm{AN} 3}$ in addition to two known isoforms designated as Rab15 ${ }^{\mathrm{CN}}$ and Rab15 ${ }^{\mathrm{AN} 1}$. Although both Rab15 ${ }^{\mathrm{AN} 2}$ and Rab15 $5^{\mathrm{AN} 3}$ contained premature termination codons, they were detected in not only neuroblastoma cells but also in normal human tissues.
\end{abstract}

Correspondence to: Dr Noriyuki Nishimura, Departments of Pediatrics and Epidemiology, Kobe University Graduate School of Medicine, 7-5-1 Kusunoki-cho, Chuo-ku, Kobe 650-0017, Japan E-mail: nnishi@med.kobe-u.ac.jp

Key words: Rab15, alternative splicing, sphere, tumor-initiating cell, neuroblastoma
One isoform was predominantly expressed in the brain and testis, while the other isoform was more specifically expressed in the brain. In neuroblastoma, Rab15 isoform balance measured by the Rab15 ${ }^{\mathrm{CN}} / \mathrm{Rab} 15^{\mathrm{AN} 1+\mathrm{AN} 2+\mathrm{AN} 3}$ ratio was significantly decreased in spheres compared to parental cells. These results suggest that Rab15 alternative splicing may serve as a biomarker to discriminate TICs from non-TICs in neuroblastoma.

\section{Introduction}

Neuroblastoma is the most commonly diagnosed cancer in the first year of life, and accounts for approximately $15 \%$ of all cancer-related deaths in the pediatric population. Although outcomes in neuroblastoma patients have improved steadily over the last 30 years, $50-60 \%$ of high-risk neuroblastoma patients are estimated to experience relapse. Consequently, their overall survival rates remain less than $40 \%$ despite more aggressive therapies (1-3). A growing body of evidence demonstrates that tumor-initiating cells (TICs) are present in most tumors and are responsible for sustaining tumor growth, progression, metastases and relapse (4-6). While many tumors regress after treatments that target proliferating tumor cells, inherent resistance of TICs leads to tumor relapse (7). Neuroblastoma TICs were recently identified as spheres grown in serum-free non-adherent culture used for neural crest stem cell growth and were shown to express stem cell markers, to have the ability to self-renew and differentiate into multiple cell types, and to form metastatic tumors in immunodeficient mice (8).

Rab family small $G$ proteins that constitute more than 60 members in humans play a key role in the spatiotemporal regulation of membrane traffic. Each Rab protein recognizes distinct subsets of intracellular membranes and controls the specific membrane transport pathways. Rab proteins function as a molecular switch cycling between 'inactive' GDP-bound and 'active' GTP-bound forms. The GTP-bound Rab protein interacts with their effector protein(s) that mediate the specific function of each Rab protein (9-11). It is becoming clear that 
the functional alteration of Rab proteins can result in several types of cancer (12). In genomic amplicons of ovarian and breast cancers, Rab25 and its effector Rab-coupling protein (RCP), which regulate the endocytic recycling pathway, are identified as cancer driver genes $(13,14)$. In melanoma, Rab27A that controls melanosome transport is implicated in cancer progression (15).

Rab15 was originally isolated as a brain-specific Rab protein regulating the endocytic recycling pathway and was recently identified as a downstream target of the neural basic helix-loop-helix (bHLH) transcription factor Atoh1 (16-18). We previously identified two alternatively spliced Rab15 isoforms in neuroblastoma cells and showed the significant correlation between Rab15 expression and neuronal differentiation (19). Alternative splicing produces multiple mRNAs from a single gene and represents the most prominent mechanism generating mRNA diversity. More than $90 \%$ of human genes undergo alternative splicing in a highly developmentand tissue-specific manner. Although the association between differential expressions of alternatively spliced isoforms and cancer progression are shown for only a handful of genes, the identification of an increasing number of cancer-associated alternative splicings has attracted considerable attention to use them as a new diagnostic and/or prognostic biomarker (20-22). In the present study, we identified and characterized two novel Rab15 isoforms in spheres of neuroblastoma cells.

\section{Materials and methods}

Neuroblastoma cells. Human neuroblastoma BE(2)-C cells were obtained from ATCC (Manassas, VA). NBTT2D cells were previously described (19). NBTT1 and NBTT3 cells were generated as previously described (19). Briefly, tumor samples were obtained from patients with high-risk neuroblastoma who were admitted to Hyogo Children's Hospital and gave written informed consent approved by the Hyogo Children's Hospital Ethics Board. The samples were handled in accordance with the Guidelines for Clinical Research of Kobe University Graduate School of Medicine. Tumor tissue samples were collected, cut into $2-3 \mathrm{~mm}^{3}$ pieces, enzymatically dissociated with Liberase DH (Roche, Mannheim, Germany) in PBS for $15-45 \mathrm{~min}$ at $37^{\circ} \mathrm{C}$ followed by the addition of $10 \%$ FBS to inhibit enzyme activity, and filtered through a $100-\mu \mathrm{m}$ cell strainer (BD Biosciences, Bedford, MA). The resulting tumor tissue cells were washed with PBS, cultured at $37^{\circ} \mathrm{C}\left(5 \% \mathrm{CO}_{2}\right.$ and $95 \%$ air) in complete medium consisting of Dulbecco's modified Eagle's medium (DMEM)/Ham's F12 (Wako Pure Chemical; Osaka, Japan) and 10\% fetal bovine serum (FBS; Invitrogen, Carlsbad, CA).

Cell culture. Neuroblastoma cells were cultured at $37^{\circ} \mathrm{C}(5 \%$ $\mathrm{CO}_{2}$ and $95 \%$ air) in complete medium consisting of DMEM/ Ham's F12 (Wako Pure Chemical) and 10\% FBS (Invitrogen) and subcultured by $0.25 \%$ trypsin-EDTA (Invitrogen). Phase-contrast images of parental cells were acquired using a BZ-9000E fluorescence microscope (Keyence, Osaka, Japan).

Sphere culture. Neuroblastoma spheres were cultured as previously described (23). Briefly, neuroblastoma cells were cultured at $37^{\circ} \mathrm{C}\left(5 \% \mathrm{CO}_{2}\right.$ and $95 \%$ air $)$ in sphere medium consisting of DMEM/Ham's F12 (3:1, Invitrogen), 100 units/ml penicillin/streptomycin (PC/SM; Invitrogen), 2\% B27 supplement (Invitrogen), $40 \mathrm{ng} / \mathrm{ml}$ basic fibroblast growth factor (bFGF; R\&D Systems, Minneapolis, MN), and $20 \mathrm{ng} / \mathrm{ml}$ epidermal growth factor (EGF; R\&D Systems), subcultured by non-enzymatic cell dissociation solution (Sigma, St. Louis, $\mathrm{MO}$ ), and maintained for $>4$ weeks in Ultra-low attachment culture dishes (CORNING, Corning, NY). Phase-contrast images of spheres were acquired using a BZ-9000E fluorescence microscope (Keyence).

cDNA cloning of novel alternatively spliced Rab15 isoforms. Total RNA from spheres of $\mathrm{BE}(2)-\mathrm{C}$ cells was isolated with the RNeasy Mini kit (Qiagen, Valencia, CA) and reverse transcribed using the PrimeScript II first strand cDNA Synthesis kit (Takara, Otsu, Japan). The full-length Rab15 ${ }^{\mathrm{CN}}$ cDNA was amplified by PCR using PrimeStar GXL DNA Polymerase (Takara) and cloned into pCMV6-AN-GFP (OriGene, Rockville, MD). The resulting plasmid DNAs from nine independent clones was sequenced using an ABI Prism 3100 Genetic Analyzer (Applied Biosystems, Foster City, CA). The cDNA sequences of Rab15 isoforms were submitted to the DDBJ/EMBL/GenBank nucleotide sequence databases under accession numbers AB678453 for Rab15 ${ }^{\mathrm{CN}}$, AB678452 for Rab15 ${ }^{\mathrm{AN} 1}$, AB672631 for Rab15 ${ }^{\mathrm{AN} 2}$, and AB672632 for Rab15 $5^{\mathrm{AN} 3}$.

Quantitative real-time RT-PCR. Human tissue total RNA was purchased from Clontech (Palo Alto, CA). Total RNA from neuroblastoma cells was isolated with the RNeasy Mini kit (Qiagen) and reverse transcribed using the QuantiTect Reverse Transcription kit (Qiagen). Real-time PCR analysis was performed with an ABI 7500 Fast Real-time PCR System (Applied Biosystems) using FastStart Universal SYBR-Green Master (Roche) according to the manufacturer's instructions. Each sample was analyzed in triplicate. Relative mRNA expression of Rab15 ${ }^{\mathrm{CN}}$, Rab15 ${ }^{\mathrm{AN} 1}, \mathrm{Rab}_{15} 5^{\mathrm{AN} 2}$, and Rab15 ${ }^{\mathrm{AN} 3}$ to PGK1 and Rab15 isoform balance were calculated by the comparative $\mathrm{C}_{\mathrm{T}}$ method. Primers for Rab15 ${ }^{\mathrm{CN}}$ (AB678453) were 5'-AGAGATACCAGACCATCACA-3' (sense) and 5'-TTCTGGTGCGTACTCATCCACGTC-3' (antisense), Rab15 ${ }^{\mathrm{AN} 1}$ (AB678452) were 5'-TACAGATCTGGGACAC TGCA-3' (sense) and 5'-CCGGCAGTGAGGTGGCATCT-3' (antisense), Rab15 ${ }^{\mathrm{AN} 2}$ (AB672631) were 5'-AGAGATACCAG ACCATCACA-3' (sense) and 5'-CCGTGGAGGCCTCATC CACGT-3' (antisense), Rab15 ${ }^{\mathrm{AN} 3}$ (AB672632) were 5'-AGAG ATACCAGACCATCACA-3' (sense) and 5'-GGTATCAGA GCTCATCCACGT-3' (antisense), and phosphoglycerate kinase 1 (PGK1, NM_000291) were 5'-GGAGAACCTCCG CTTTCAT-3' (sense) and 5'-GCTGGCTCGGCTTTAACC-3' (antisense).

\section{Results}

Identification of novel alternatively spliced Rab15 isoforms. We previously identified two alternatively spliced Rab15 isoforms designated as Rab15 ${ }^{\mathrm{CN}}$ and Rab15 ${ }^{\mathrm{AN}}$ and showed that Rab15 isoform balance measured by the Rab15 ${ }^{\mathrm{CN}} / \mathrm{Rab} 15^{\mathrm{AN}}$ ratio was significantly increased during neuronal differentiation of neuroblastoma cells (19). As aberrant alternative splicing is 
A

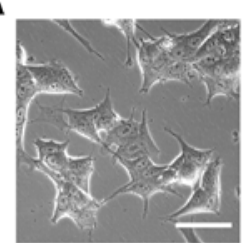

Parental cells
Spheres

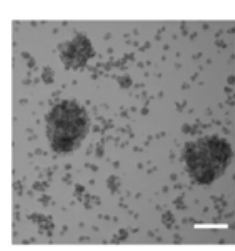

B

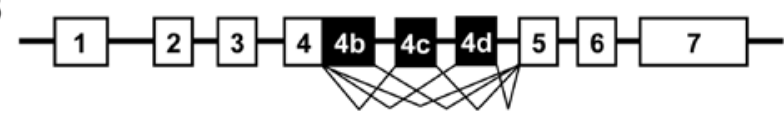

$\operatorname{Rab}^{\mathrm{CN}}$

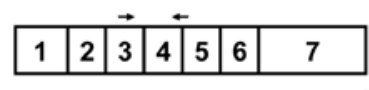

ORF: $639 \mathrm{bp}$

Rab15 ${ }^{\text {AN1 }}$

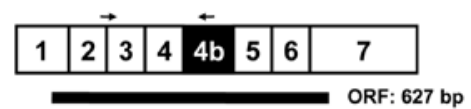

Rab15 ${ }^{\text {AN2 }}$

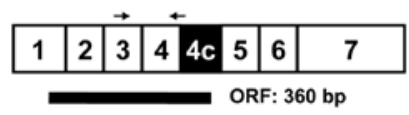

Rab15 ${ }^{\text {AN3 }}$

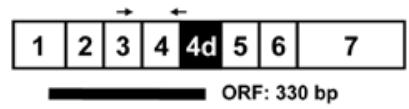

Figure 1. Identification of novel alternatively spliced Rab15 isoforms. (A) $\mathrm{BE}(2)-\mathrm{C}$ cells were cultured either in a $10 \%$ serum adherent condition for 3 days (parental cells) or in a serum-free non-adherent condition over 4 weeks (spheres) and examined by phase-contrast microscopy. The images shown are representative of three independent experiments. Scale bar, $100 \mu \mathrm{m}$. (B) The structure of the Rab15 gene, Rab15 ${ }^{\mathrm{CN}}, \mathrm{Rab} 15^{\mathrm{AN} 1}, \mathrm{Rab} 15^{\mathrm{AN} 2}$, and Rab15 ${ }^{\mathrm{AN}}$. Arrows indicate the primers used for a real-time RT-PCR. The sequences of the primers are provided in the Materials and methods.

intimately associated with an increasing number of cancers, its use as a new diagnostic and/or prognostic biomarker has attracted considerable attention. Therefore, we examined cancer-associated changes of Rab15 alternative splicing in spheres of neuroblastoma cells, in which TICs were highly enriched (8). When BE(2)-C cells were cultured in a serumfree non-adherent condition, they efficiently formed spheres as previously described (23) (Fig. 1A). To detect cancer-associated changes of Rab15 alternative splicing, we first cloned the fulllength Rab15 ${ }^{\mathrm{CN}}$ (AB678453) cDNA from spheres of BE(2)-C cells by RT-PCR. DNA sequencing of nine independent clones revealed the presence of three clones of novel Rab15 isoforms in addition to four clones of Rab15 ${ }^{\mathrm{CN}}$ and two clones of Rab15 ${ }^{\mathrm{AN}}$. One clone contained an 85-bp insertion (exon 4c) between exon 4 and exon 5 with a 360 bp open reading frame (ORF), whereas two clones had the identical 86-bp insertion (exon 4d) between exon 4 and exon 5 with a 330 bp ORF. Here, we designated exon 4c- and exon 4d-inserted clones as $\mathrm{Rab15}^{\mathrm{AN2}}$ (AB672631) and Rab15 ${ }^{\mathrm{AN} 3}$ (AB672632), respectively. Accordingly, we re-designated Rab15 ${ }^{\mathrm{AN}}$ with a $627 \mathrm{bp} \mathrm{ORF}$ as Rab15 $^{\text {AN1 }}$ (AB678452) (Fig. 1B).

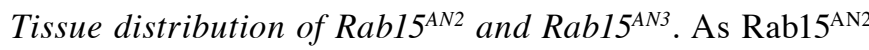
and Rab1 $5^{\mathrm{AN} 3}$ contained premature termination codons that would cause the resulting mRNAs to be degraded by nonsense-mediated mRNA decay (NMD) $(24,25)$, we examined
A

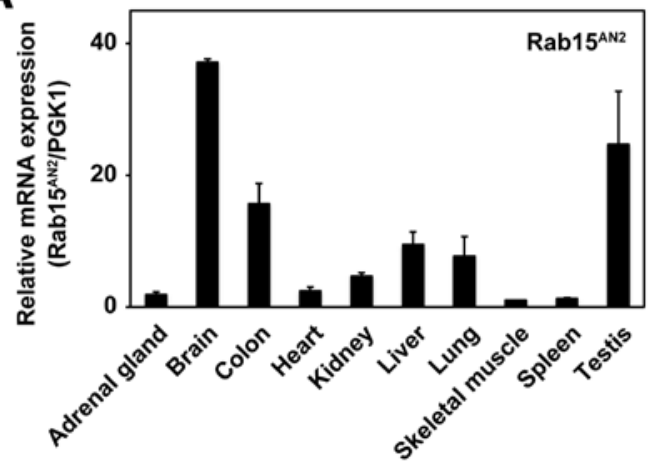

B

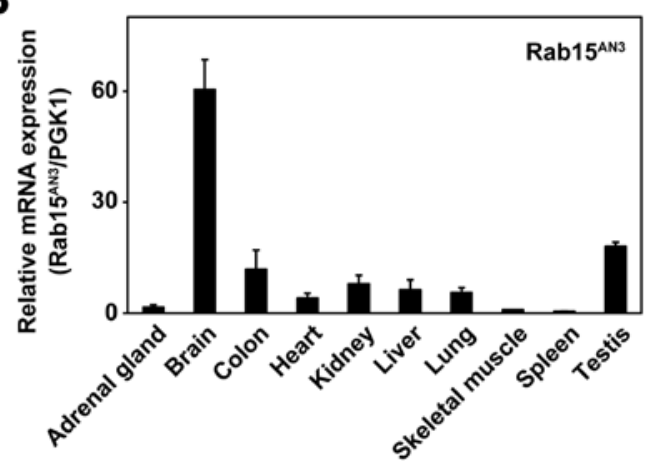

Figure 2. Tissue distribution of Rab15 $5^{\mathrm{AN} 2}$ and Rab15 $5^{\mathrm{AN} 3}$. The relative mRNA expression of Rab15 $5^{\mathrm{AN} 2}$ to PGK1 (A) and Rab15 ${ }^{\mathrm{AN} 3}$ to PGK1 (B) in various human tissues was analyzed by quantitative real-time RT-PCR. The mean expression in skeletal muscle was set to 1 . The data shown are means \pm SD of three independent experiments.

whether they were also expressed in normal human tissues by a quantitative real-time RT-PCR using the Rab15 isoformspecific primers (Fig. 1B). Rab15 $5^{\mathrm{AN} 2}$ and Rab15 $5^{\mathrm{AN} 3}$ were detected in normal human tissues and showed a distinct tissue distribution pattern (Fig. 2). Rab15 $5^{\mathrm{AN} 2}$ was predominantly expressed in the brain and testis, while Rab15 ${ }^{\mathrm{AN} 3}$ was more specifically detected in the brain (Fig. 2). Together with the brain-specific Rab15 ${ }^{\mathrm{CN}}$ and testis-specific Rab15 ${ }^{\mathrm{AN} 1}$ expression (19), these results suggested that there were at least four alternatively spliced Rab15 isoforms, Rab15 ${ }^{\mathrm{CN}}$, Rab15 $5^{\mathrm{AN} 1}$, Rab15 ${ }^{\mathrm{AN} 2}$, and Rab15 $5^{\mathrm{AN} 3}$, with distinct tissue distribution in humans.

Rab15 alternative splicing in parental cells and spheres of BE(2)-C cells. To analyze Rab15 alternative splicing in parental cells and spheres of BE(2)-C cells, we examined the expression of all Rab15 isoforms. In parental cells, Rab15 ${ }^{\mathrm{CN}}$ was the most prevalent isoform and was expressed 13.2-fold more highly than the second most prevalent isoform, Rab15 $5^{\mathrm{AN1}}$ (Fig. 3A). In spheres, Rab15 ${ }^{\mathrm{CN}}$ was also the most prevalent isoform but was only expressed 6.1-fold more than the second prevalent isoform Rab15 ${ }^{\mathrm{AN} 3}$ (Fig. 3B), suggesting that Rab15 alternative splicing was considerably altered in spheres of $\mathrm{BE}(2)-\mathrm{C}$ cells.

Rab15 isoform balance in normal human tissues. To evaluate Rab15 alternative splicing further, we examined Rab15 isoform balance measured by the Rab15 $5^{\mathrm{CN} / \mathrm{Rab} 15^{\mathrm{AN} 1+\mathrm{AN} 2+\mathrm{AN} 3}}$ ratio in various human tissues. Consistent with our previous 
A

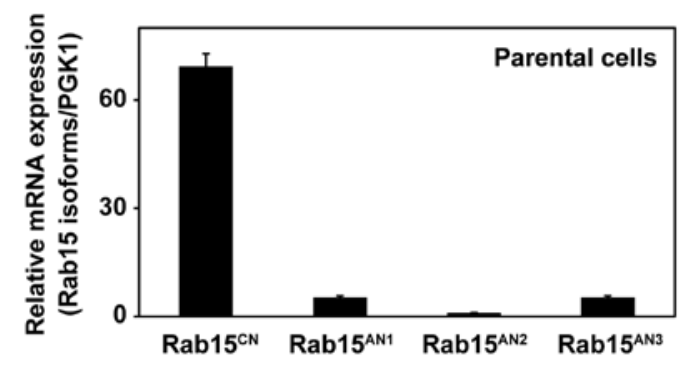

B

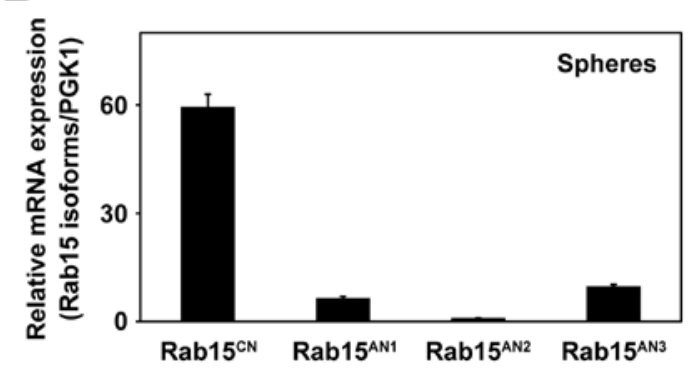

Figure 3. Rab15 alternative splicing in parental cells and spheres of BE(2)-C cells. The relative mRNA expression of Rab15 ${ }^{\mathrm{CN}}, \mathrm{Rab}_{15}^{\mathrm{AN} 1}, \mathrm{Rab}^{\mathrm{AN} 2}$, and Rab15 $5^{\mathrm{AN} 3}$ to PGK1 was analyzed by quantitative real-time RT-PCR. The mean expression of Rab15 $5^{\mathrm{AN} 2}$ was set to 1 . The data shown are the means $\pm \mathrm{SD}$ of three independent experiments.

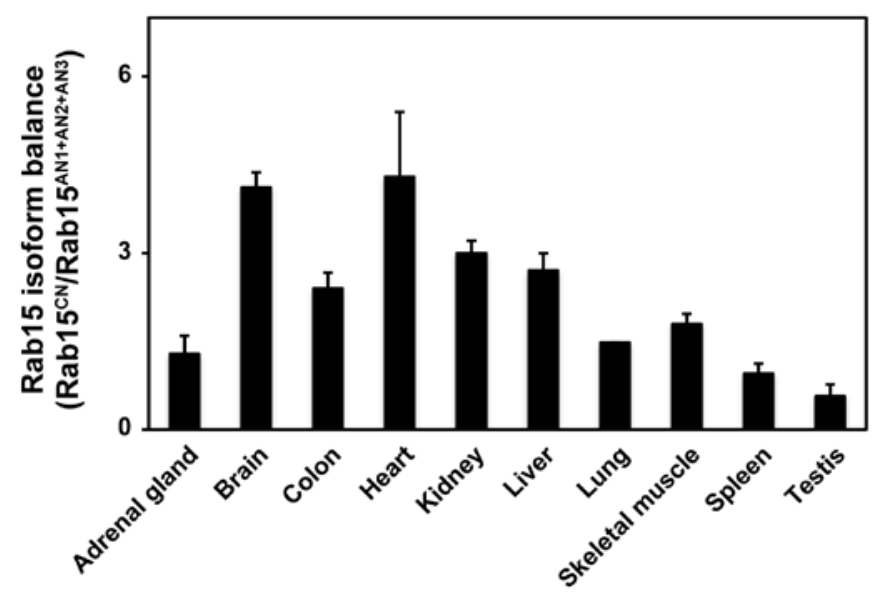

Figure 4. Rab15 isoform balance in normal human tissues. Rab15 isoform balance measured by the Rab15 ${ }^{\mathrm{CN}} / \mathrm{Rab} 15^{\mathrm{AN} 1+\mathrm{AN} 2+\mathrm{AN} 3}$ ratio was analyzed by quantitative real-time RT-PCR in various human tissues. The data shown are the means \pm SD of three independent experiments.

observation (19), it was considerably varied, ranging from 0.6 in the testis to 4.3 in the heart (Fig. 4), suggesting that Rab15 alternative splicing was subjected to the tissue-specific regulation.

Altered Rab15 isoform balance in spheres of neuroblastoma cells. As Rab15 isoform balance measured by the Rab15 $\mathrm{CN} /$ Rab15 $5^{\mathrm{AN} 1}$ ratio was significantly increased during neuronal differentiation of neuroblastoma cells (19), we here examined the Rab15 isoform balance measured by the Rab15 $5^{\mathrm{CN}}$ / Rab15 $5^{\mathrm{AN} 1+\mathrm{AN} 2+\mathrm{AN} 3}$ ratio in parental cells and spheres of neuroblastoma cells. Because neuroblastoma cells displayed a
Table I. Summary of cells isolated from clinical samples.

\begin{tabular}{lclcc}
\hline Cells & $\begin{array}{c}\text { Age } \\
\text { (years) }\end{array}$ & Gender & $\begin{array}{c}\text { Tumor risk } \\
\text { group }\end{array}$ & $\begin{array}{c}\text { Specimen } \\
\text { type }\end{array}$ \\
\hline NBTT1 & 6 & Male & High-risk & Adrenal gland \\
NBTT3 & 2 & Female & High-risk & Adrenal gland \\
\hline
\end{tabular}

The tumor risk group was based on the Children's Oncology Group Neuroblastoma Risk Stratification System (33). NBTT1 cells were derived from the same patient as the NBBM2 bone marrow cells described in our previous report (19).

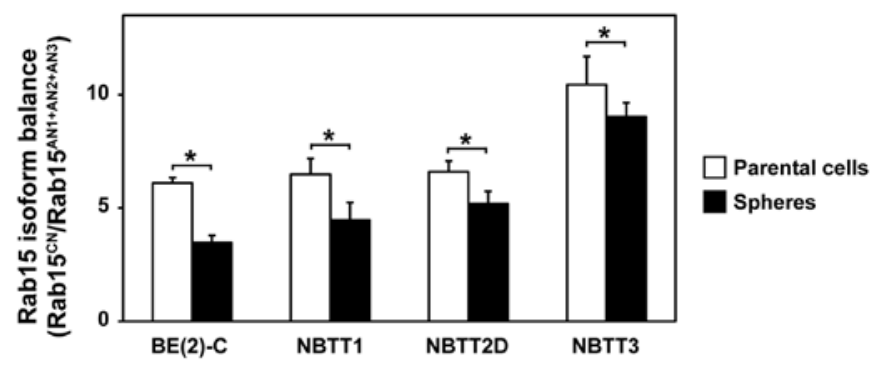

Figure 5. Altered Rab15 isoform balance in spheres of neuroblastoma cells. Rab15 isoform balance measured by the Rab15 ${ }^{\mathrm{CN}} / \mathrm{Rab} 15^{\mathrm{AN} 1+\mathrm{AN} 2+\mathrm{AN} 3}$ ratio was analyzed by quantitative real-time RT-PCR. The data shown are means \pm SD of three independent experiments. ${ }^{*} \mathrm{P}<0.05$, by the Student's $\mathrm{t}$ test.

considerable heterogeneity, we used three additional neuroblastoma cell lines designated as NBTT1, NBTT2D, and NBTT3 from high-risk patients in addition to $\mathrm{BE}(2)-\mathrm{C}$ cells (Table I). Compared to parental cells, Rab15 isoform balance was significantly decreased in spheres of all BE(2)-C, NBTT1, NBTT2D, and NBTT3 cells (Fig. 5), suggesting that Rab15 alternative splicing was altered in spheres of neuroblastoma cells.

\section{Discussion}

In the present study, we found that Rab15 alternative splicing generated at least two novel isoforms in addition to two known isoforms and was altered in spheres of neuroblastoma cells. Neuroblastoma is believed to originate from neural crest cells that normally undergo sympathoadrenal differentiation (1-3). Although it is currently unclear whether neuroblastoma TICs arise directly from the normal neural crest cells or are derived from the de-differentiation of already transformed cells, TICs can be isolated as spheres (8). As spheres and parental cells were enriched in TICs and non-TICs, Rab15 alternative splicing was likely altered during the differentiation of neuroblastoma TICs into non-TICs.

Transcriptional profiling of normal and cancer cells leads to the identification of an increasing number of cancer-associated alternative splicing in a variety of cancers. Although these alternative splicings may not play any significant role in cancer progression, the association between differential expression of alternatively spliced isoforms and cancer progression has been validated for several genes (20-22). Aberrant expression of mouse double minute 2 (MDM2) isoforms is correlated with a poor prognosis in breast cancer (26). Isoform balance 
of hyaluronan synthase 1 (HAS1) and receptor for hyaluronanmediated motility (RHAMM) is shown to be a prognostic marker for multiple myeloma $(27,28)$. In neuroblastoma, the expression of an alternatively spliced isoform of tumor suppressor $\mathrm{p} 73, \Delta \mathrm{Np} 73$, is associated with reduced survival (29). Furthermore, cyclooxygenase inhibitors were shown to downregulate $\Delta \mathrm{Np} 73$ expression and induce the other $\mathrm{p} 73$ isoform, TAp73, providing a possible therapeutic way to modulate and/or correct cancer-associated alternative splicing (30). In the case of Rab15, whether alternatively spliced isoforms Rab15 $5^{\mathrm{AN} 1}$, Rab15 ${ }^{\mathrm{AN} 2}$, and Rab15 ${ }^{\mathrm{AN} 3}$ have actual roles in neuroblastoma progression or are merely consequences of transformation is an open question for future study.

While we previously showed that Rab $15^{\mathrm{CN}}$ expression was correlated with neuronal differentiation of neuroblastoma cells (19), Rab15 was recently identified as a downstream target of neural bHLH transcription factor Atoh1 that specified distinct neuronal subtypes of the proprioceptive pathway (18). Atoh1 expression is known to control the normal development of the cerebellum and prevent medulloblastoma progression (31). In neuroblastoma cells, Atoh1 expression is regulated by $\beta$-catenin expression (32). It is tempting to speculate that the $\beta$-catenin-Atoh1-Rab15 system participates in some aspects of neuroblastoma progression. Together with our previous findings, the present study revealed that Rab15 isoform balance measured by the Rab15 ${ }^{\mathrm{CN}} / \mathrm{Rab} 15^{\mathrm{AN} 1+\mathrm{AN} 2+\mathrm{AN} 3}$ ratio was significantly increased during differentiation of neuroblastoma cells, the differentiation of TICs into non-TICs as well as the neuronal differentiation (19). Because prognosis of neuroblastoma correlates with the degree of differentiation, Rab15 isoform balance may deserve further evaluation as a new prognostic biomarker.

In summary, we identified four Rab15 isoforms, Rab15 ${ }^{\mathrm{CN}}$, Rab15 ${ }^{\mathrm{AN} 1}, \mathrm{Rab}^{\mathrm{AN} 2}$, and Rab15 ${ }^{\mathrm{AN} 3}$, in neuroblastoma cells, and demonstrated that Rab15 isoform balance measured by the $\mathrm{Rab} 15^{\mathrm{CN}} / \mathrm{Rab} 15^{\mathrm{AN} 1+\mathrm{AN} 2+\mathrm{AN} 3}$ ratio was significantly decreased in spheres of neuroblastoma cells. The present study suggests that Rab15 alternative splicing may serve as a biomarker to discriminate TICs from non-TICs in neuroblastoma.

\section{Acknowledgements}

This study was supported in part by Grants-in-Aid for Scientific Research from the Ministry of Education, Culture, Sports, Science and Technology of Japan, and grants from the Showahokokai, the Hyogo Prefecture Health Promotion Association, and the Foundation for Promotion of Cancer Research.

\section{References}

1. Colon NC and Chung DH: Neuroblastoma. Adv Pediatr 58: 297-311, 2011.

2. Maris JM, Hogarty MD, Bagatell R and Cohn SL: Neuroblastoma. Lancet 369: 2106-2120, 2007.

3. Brodeur GM: Neuroblastoma: biological insights into a clinical enigma. Nat Rev Cancer 3: 203-216, 2003.

4. Visvader JE and Lindeman GJ: Cancer stem cells in solid tumours: accumulating evidence and unresolved questions. Nat Rev Cancer 8: 755-768, 2008.

5. Alison MR, Islam S and Wright NA: Stem cells in cancer: instigators and propagators? J Cell Sci 123: 2357-2368, 2010.

6. Bomken S, Fiser K, Heidenreich O and Vormoor J: Understanding the cancer stem cell. Br J Cancer 103: 439-445, 2010.
7. Maugeri-Saccà $\mathrm{M}$, Vigneri $\mathrm{P}$ and De Maria R: Cancer stem cells and chemosensitivity. Clin Cancer Res 17: 4942-4947, 2011.

8. Hansford LM, McKee AE, Zhang L, et al: Neuroblastoma cells isolated from bone marrow metastases contain a naturally enriched tumor-initiating cell. Cancer Res 67: 11234-11243, 2007.

9. Takai Y, Sasaki T and Matozaki T: Small GTP-binding proteins. Physiol Rev 81: 153-208, 2001.

10. Nishimura $\mathrm{N}$ and Sasaki T: Rab family small G proteins in regulation of epithelial apical junctions. Front Biosci 14: 2115-2129, 2009.

11. Hutagalung AH and Novick PJ: Role of rab GTPases in membrane traffic and cell physiology. Physiol Rev 91: 119-149, 2011.

12. Chia WJ and Tang BL: Emerging roles for Rab family GTPases in human cancer. Biochim Biophys Acta 1795: 110-116, 2009

13. Cheng K, Lahad J, Kuo W, et al: The RAB25 small GTPase determines aggressiveness of ovarian and breast cancers. Nat Med 10: 1251-1256, 2004.

14. Zhang J, Liu X, Datta A, et al: RCP is a human breast cancerpromoting gene with Ras-activating function. J Clin Invest 119: 2171-2183, 2009

15. Akavia UD, Litvin O, Kim J, et al: An integrated approach to uncover drivers of cancer. Cell 143: 1005-1017, 2010.

16. Elferink LA, Anzai K and Scheller RH: rab15, a novel low molecular weight GTP-binding protein specifically expressed in rat brain. J Biol Chem 267: 5768-5775, 1992.

17. Zuk PA and Elferink LA: Rab15 differentially regulates early endocytic trafficking. J Biol Chem 275: 26754-26764, 2000.

18. Lai HC, Klisch TJ, Roberts R, Zoghbi HY and Johnson JE: In vivo neuronal subtype-specific targets of Atoh1 (Math1) in dorsal spinal cord. J Neurosci 31: 10859-10871, 2011.

19. Nishimura N, Pham TVH, Hartomo TB, et al: Rab15 expression correlates with retinoic acid-induced differentiation of neuroblastoma cells. Oncol Rep 26: 145-151, 2011.

20. Pajares MJ, Ezponda T, Catena R, Calvo A, Pio R and Montuenga LM: Alternative splicing: an emerging topic in molecular and clinical oncology. Lancet Oncol 8: 349-357, 2007.

21. David CJ and Manley JL: Alternative pre-mRNA splicing regulation in cancer: pathways and programs unhinged. Genes Dev 24: 2343-2364, 2010.

22. Ward AJ and Cooper TA: The pathobiology of splicing. J Pathol 220: 152-163, 2010.

23. Nishimura N, Hartomo TB, Pham TVH, et al: Epigallocatechin gallate inhibits sphere formation of neuroblastoma BE(2)-C cells. Environ Health Prev Med: Sep 10, 2011 (Epub ahead of print).

24. McGlincy NJ and Smith CWJ: Alternative splicing resulting in nonsense-mediated mRNA decay: what is the meaning of nonsense? Trends Biochem Sci 33: 385-393, 2008.

25. Nicholson P, Yepiskoposyan H, Metze S, Zamudio Orozco R, Kleinschmidt N and Mühlemann O: Nonsense-mediated mRNA decay in human cells: mechanistic insights, functions beyond quality control and the double-life of NMD factors. Cell Mol Life Sci 67: 677-700, 2010

26. Lukas J, Gao DQ, Keshmeshian M, et al: Alternative and aberrant messenger RNA splicing of the $\mathrm{mdm} 2$ oncogene in invasive breast cancer. Cancer Res 61: 3212-3219, 2001.

27. Maxwell CA, Rasmussen E, Zhan F, et al: RHAMM expression and isoform balance predict aggressive disease and poor survival in multiple myeloma. Blood 104: 1151-1158, 2004.

28. Adamia S, Reiman T, Crainie M, Mant MJ, Belch AR and Pilarski LM: Intronic splicing of hyaluronan synthase 1 (HAS1): a biologically relevant indicator of poor outcome in multiple myeloma. Blood 105: 4836-4844, 2005.

29. Casciano I, Mazzocco K, Boni L, et al: Expression of DeltaNp73 is a molecular marker for adverse outcome in neuroblastoma patients. Cell Death Differ 9: 246-251, 2002.

30. Lau LMS, Wolter JK, Lau JTML, et al: Cyclooxygenase inhibitors differentially modulate p73 isoforms in neuroblastoma. Oncogene 28: 2024-2033, 2009.

31. Flora A, Klisch TJ, Schuster G and Zoghbi HY: Deletion of Atoh1 disrupts Sonic Hedgehog signaling in the developing cerebellum and prevents medulloblastoma. Science 326: 1424-1427, 2009.

32. Shi F, Cheng Yf, Wang XL and Edge ASB: Beta-catenin up-regulates Atoh1 expression in neural progenitor cells by interaction with an Atoh1 3' enhancer. J Biol Chem 285: 392-400, 2010.

33. Weinstein JL, Katzenstein HM and Cohn SL: Advances in the diagnosis and treatment of neuroblastoma. Oncologist 8: 278-292, 2003. 